\title{
MULTISCALE GIS-BIM METHODOLOGICAL APPROACHES AND DIGITAL SYSTEMS FOR THE KNOWLEDGE OF THE MODERN ARCHITECTURAL HERITAGE IN ITALY. THE RURAL VILLAGE "LA MARTELLA" IN MATERA
}

\author{
R. Pontrandolfi ${ }^{1, *}$ \\ ${ }^{1}$ Architecture Department, Roma Tre University, Rome, Italy - raffaele.pontrandolfi@uniroma3.it
}

Commission II - WG II/8

\begin{abstract}
KEY WORDS: ICT (Information and Communications Technology) tools and methodologies, GIS (Geographical Information System), BIM (Building Information Modeling), Modern minor heritage, Digital documentation, Italian architectural Neorealism
\end{abstract}

\begin{abstract}
:
The use of digital tools and approaches related to the ICT field is now of particular importance for the knowledge and enhancement of the modern architectural heritage. The contribution intends to focus on the theme of cognitive analysis and digital documentation of some examples of public residential buildings of historical and testimonial value of the period following the second World War, in Italy, in order to define appropriate recovery strategies. Unlike buildings of historical-monumental importance, which have been the subject of studies and surveys involving the use of digital tools for several years now, little interest is still attributed to the knowledge of the building heritage of the second half of the Twentieth Century to which historical value is attributed. The interventions in the 1950s by INA Casa and U.N.R.R.A. Casas, in Italy, constitute interesting case studies that are worthy of further research and cognitive analysis based on holistic and multi-scalar approaches. In this context, the surveys and research in progress on the historical buildings of the rural village "La Martella" in Matera (1951-55) are an interesting example of experimentation using GIS-BIM digital platforms for the implementation of a multiscale knowledge methodology (from the territorial scale, to urban blocks to individual buildings) that provides for the structuring and implementation of an integrated information database (Common Data Environment) aimed at defining recovery strategies for the protection and enhancement of the historical buildings of the village, through the concept of interoperability for the systematization of archive sources and data obtained through surveys on the existing situation.
\end{abstract}

\section{INTRODUCTION}

1.1 ICT digital systems for the knowledge and management of the modern architectural heritage

The proposed contribution is related to the knowledge, recovery and enhancement of the modern architectural heritage, in this case related to social housing, through the adoption of approaches, methodologies and tools related to the ICT (Information and Communications Technology) field. This area of investigation is still in its research and experimentation phase, especially in relation to the current problem regarding the management of the public residential heritage of the last sixty years, which in many cases has become private property, and to the objective of a recovery and re-functionalisation that is compatible with the original intended use, so as to avoid further land consumption and rethink the often critical relationship between public space-city-countryside that was originally addressed with the implementation of these interventions ( $\mathrm{Di}$ Biagi, 2001; Berdelli et al., 2003; Mininni, 2015). Compared to the Italian and European minor and monumental historical buildings, which have already been widely investigated and studied for several years also with the aid of digital tools and protocols (Gigliarelli et al, 2017; Dore, Murphy, 2012), the research and analysis of the wide range of urban and rural settlements related to the Italian Reconstruction period during the second post-war years, in this case the public housing interventions of INA Casa, U.N.R.R.A. Casas (Comitato Amministrativo Soccorso Ai Senza Tetto) or the IACP (Istituto
Autonomo Case Popolari), are still little pursued and play a secondary role in the long-standing debate on the recovery of cities or important areas thereof. Interest in the rediscovery of a period of fundamental importance for the development of Italian architecture, lies in the innovative approach for the period that many of these interventions represented, both in terms of urban and typological experimentation as well as the expressiveness of the language used, not least for the "hybrid" approach used in the building site, straddling standardization, in particular with the use of reinforced concrete, and a reinterpretation of the local architectural elements (Di Biagi, 2001; Tafuri, 2002; Raguso, 2010). It is therefore essential to safeguard some of the most emblematic cases of this architectural season, above all for their historical-testimonial value, also in virtue of their not always apt state of conservation, often encountering incongruous tampering and additions carried out over the decades and which have brought them to the current state of neglect and widespread degradation. Originally conceived as urban and suburban settlements during the fifties, and in relation to the reconstruction and expansion of the city in the second half of the Twentieth Century (Di Biagi, 2001; Raguso, 2010, Bilò, Vadini, 2013), today these interventions are in several cases an integral part of the contemporary city, thus requiring integrated actions of redevelopment, building recovery and refunctionalisation that are compatible with the characteristics and uses originally intended. In this perspective, the application of digital methodologies and systems, for the surveys and cognitive analyses underlying the strategies for recovery and reuse, assumes a fundamental role. Most of the documentary

\footnotetext{
* Corresponding author
} 
sources, project graphics and photographic material of these interventions are often stored in separate archives and fonds, making it more difficult to find them for consultation. This would require the use of a structured, holistic and implementable digital database for an integrated digital management of very heterogeneous sources. This contribution aims to investigate the joint use of GIS and BIM technologies and platforms, which today play a fundamental role both for the systematic knowledge of modern building and for the targeted planning of strategies for the recovery of the heritage under investigation (Brumana et al., 2013; Baik et al., 2015). The research experience, currently still undergoing experimentation, is related to the rural village of "La Martella" in Matera.

\subsection{The use of GIS and BIM methodologies and tools for} the mapping, surveying and recovery of the existing heritage

In the context of the ongoing research, use of methodological approaches related to the ICT field, in particular the digital GIS and BIM systems, is of fundamental importance as a possible means to formulating a survey and a structured analysis of the existing buildings of the case study. The use of both these technologies, however, stems from partially different needs and goals, especially in relation to the different type of survey carried out on a precise scale of intervention. GIS and BIM systems are in fact used for different aims, but both share some ontological aspects: they are based on the concept of "information" and in common have the correlation of a database that refers to a representation of geometric entities that can be respectively points, lines and polygons for GIS, and parametric objects for BIM environments (Saygi et al., 2013; Baik et al., 2015; Barazzetti, Banfi, 2017). Both these digital technologies are based on the use of geometrical-semantic databases but, as mentioned above, they refer to different fields of investigation. While the GIS systems are created and evolve mainly via use of 2D digital models for the modeling of the existing heritage at a territorial scale and have been in circulation for almost thirty years, BIM on the other hand, is a more recent technology and is mainly used in the field of new constructions, on an architectural and detail scale, through the use of 3D-semantic models referred to individual buildings or building complexes. Another important aspect that highlights the difference between these two information systems is the different degree of accuracy in the management and implementation of non-geometrical attributes on the one hand, and the level of graphic detail achievable in relation to geometric entities on the other; while GIS are based mainly on a high capacity of implementation and probing of spatial data and related attributes, to the detriment of a more limited geometric processing capacity, BIM technologies, on the contrary, allow for the achievement of a high geometric detail (through the concept of Level Of Development), to the detriment of a greater deficiency in the management and implementation of non-constructive attributes (Saygi et al., 2013; Volk et al., 2014; Spallone et al., 2016; Tobiáš, 2016). Despite these significant differences in terms of the management of the information processes used, recent studies and sector experiments (Kolbe et al., 2005; Torabi Moghadam et al., 2016; Barazzetti, Banfi, 2017; Vacca et al., 2018) have demonstrated the current importance of the search for a possible interoperability between these two types of digital systems, especially in relation to the targeted management of the constructed, historical and modern heritage. The development of holistic and implementable databases, based on the mutual principle of exchanging and sharing "information" from different and heterogeneous sources, would allow for a structured systematization and cataloging of the data found for their effective use and interrogation over time. The joint use of both technologies is therefore recommended for the cognitive analysis as well as for the survey of the existing heritage and, through the extrapolation of quanti-qualitative data, for the development of strategies for the recovery and management of this heritage. Currently the integration between the two software environments is still under development, especially with regards the transfer of information between the two systems (Tobiáš, 2016; Barazzetti, Banfi, 2017; Ma, Ren, 2017; Matrone et al., 2019).

\section{THE AIM OF INVESTIGATION}

2.1 The architectural experience of Reconstruction in Italy in the second post-war period. Urban (the INA Casa Plan, 1949-63) and suburban (U.N.R.R.A. Casas interventions, 1947-1962) settlement models

The historical reference period of the case study examined is related to the Reconstruction period in Italy, following the Second World War, during the fifties and sixties. Within this precise time framework, there were various architectural trends and initiatives by government institutions in relation to the urgent problem of housing. On the one hand, the urban-typological study for the construction of new settlements, attempted to combine recent organicist oriented experiences in Europe (Alvar Aalto, Jørn Utzon) with the previous projects and studies on the garden-city of the first post-war period (F.L. Wright, Lewis Mumford), and on the other there was a rediscovery and reinterpretation of the vernacular tradition, through a "sincere" and functional language representing the class for which the new interventions were intended (Di Biagi, 2001; Tafuri, 2002). In particular, there was a double approach to the solution of the housing issue that was to be implemented through different initiatives, linked together both from a temporal point of view and, often, through the involvement of the creators themselves. The first, corresponds to the Marshall Plan (1947-51), destined specifically to solving the housing emergency of the populations affected by the war through the funds of the ERP (European Recovery Program) and with the establishment of the U.N.R.R.A. Casas (Comitato Amministrativo Soccorso Ai Senza Tetto), between 1947 and 1962, interventions were planned especially in the rural areas of central-southern Italy. In close connection with this first initiative, the establishment a few years later of the "Cassa del Mezzogiorno" (Law n. 646, August 1950) and the related Agrarian Reform (Law n. 841, October 1950), attempted to partially solve the housing problem of economically depressed areas through the redistribution of land to farmers and the consequent construction of rural villages (Talamona, 2001; Bilò, Vadini, 2013). The other main initiative, parallel to the previous ones, was instead the direct intervention of the State, through the institution of the Fanfani Law n. 43 of February 1949 and the related INA Casa Plan (1949-63) - the largest public housing programme in Italian history. Their chief purpose was to achieve a dual goal: on the one hand, the construction of medium-large sized neighbourhoods to accommodate the masses of displaced people or those coming from the southern regions, and on the other, the use of a traditional building site, with the exclusion of prefabrication, to increase the employment of workforce and thus solve the problem of unemployment (Di Biagi, 2001; Raguso, 2010). These different operational trends are reflected in the related projects at different levels of intervention: on the one hand, the suburban settlements such as the rural villages of "La Martella" (1951-55) and "Venusio" (1954-57) in Matera, "Orto Nuovo" in Cutro (1950), the semi-rural nucleus of "San Basilio" in Rome (1951) or the villages of "Fucino" in Abruzzo (1953); on the other, urban districts such as "Valco San Paolo" (1949-52), "Tiburtino" (1949-54) and "Tuscolano" (1950-60) in Rome, the Milanese districts of "Harrar" (1951-55) and "Cesate" (1951-57), "Borgo Panigale" (1951) and "Cavedone" (1957-60) in Bologna, 
"San Marco" in Mestre (1951-61) or "La Falchera" in Turin (1950-56) and the "Isolotto" in Florence (1954), just to mention the most important ones. Subsequent socio-economic changes on a national scale, together with the reform of the building authorities (the Sullo Law of 1962) will see the transformation of INA Casa into GesCaL, and U.N.R.R.A. Casas into ISES (Istituto per lo Sviluppo dell'Edilizia Sociale), thus determining the end of this important experience in urban planning and construction of the second post-war period (Bilò, Vadini, 2013).

2.2 The rural U.N.R.R.A. Casas village of "La Martella" in Matera (1951-55). From the original settlement, to its current degradation, to possible recovery scenarios

Among the most emblematic examples attributable to the first of these two cases, is the urban-architectural experience of the settlement of "La Martella" which certainly constitutes an important intervention both from the perspective of the interdisciplinary approach and of the typological-formal experimentation used. This new rural suburban nucleus is historically linked to the story of the relocation of the inhabitants of the Sassi district in Matera, following the visit of President Alcide De Gasperi in 1950, and the start of the land reform programme in Southern Italy. A decisive role within this framework was played by the intellectual Adriano Olivetti (president of INU - Istituto Nazionale di Urbanistica - and vicepresident of the U.N.R.R.A. Casas committee), promoter of territorial planning based on the model of the pre-war American experiences of the Tennessee Valley Authority (Pontrandolfi, 2002; Doria, 2010). The establishment of a special Study Commission composed of various figures of note (F. Friedmann, T. Tentori, F. Nitti, L. Quaroni, F. Gorio among others) for the investigation of the precarious housing conditions of the Sassi district, lead to the decision to move the inhabitants into rural villages outside the city: of the six settlements originally planned, only four were built ("La Martella", "Venusio", "Picciano" A and B). The genesis of the village of "La Martella" (Figure 1) after an initial hypothesis by the architect Ettore Stella, who died prematurely, saw its inception by a group of Roman architects (Federico Gorio, Luigi Agati, P.M. Lugli, Michele Valori) from the Centro Studi per l'Abitazione led by Ludovico Quaroni, most of whom had just previously taken part in the Roman intervention of the INA Casa "Tiburtino" district, considered a manifesto of neo-realist architecture (Tafuri, 2002; Raguso, 2010). Compared to the previous intervention, the approach to design, in the case of the rural village, saw a more direct involvement of the future inhabitants, thereby avoiding ideological linguistic choices and artifacts, thus facing an orography on a territorial scale and the reinterpretation of local vernacular typologies in a contemporary key also through reference to Anglo-Saxon and North European organicist architecture. This first example of "participatory planning" on a national scale, is of fundamental importance specifically for the urban and typological choices made with reference to the suggestions of its future inhabitants, as opposed to the "Tiburtino" intervention of which the new rural village constitutes a sort of "autocriticism" by the creators themselves (De Carlo, 1954; Gorio, 1954; Aymonino, 1959): the choice of a sole type of single-family terraced house on two floors, with an agricultural annex and separate stable, the provision of common bakeries at the crossroads and, above all, the reinterpretation of the "neighbourhood units" typical of the archaic settlement structure of the "Sassi", was to constitute some of the main features of this intervention (Figure 2). From a design point of view, different variations of the same typology of housing were used for the farmers, and another for the artisans; the new settlement was also equipped with some collective civic and religious facilities (a church, a civic centre with shops, a post office, police headquarters, three nursery schools, a medical clinic). The choice of traditional technologies, use of local materials (tuff for the masonry, wooden frames), together with the insertion of some reinforced concrete inserts (the SAP brick slab) was to be the stylistic feature of this intervention that attempted to avoid any artificial solution, trying instead to relate with the existing context (Talamona, 2001; Raguso, 2010).

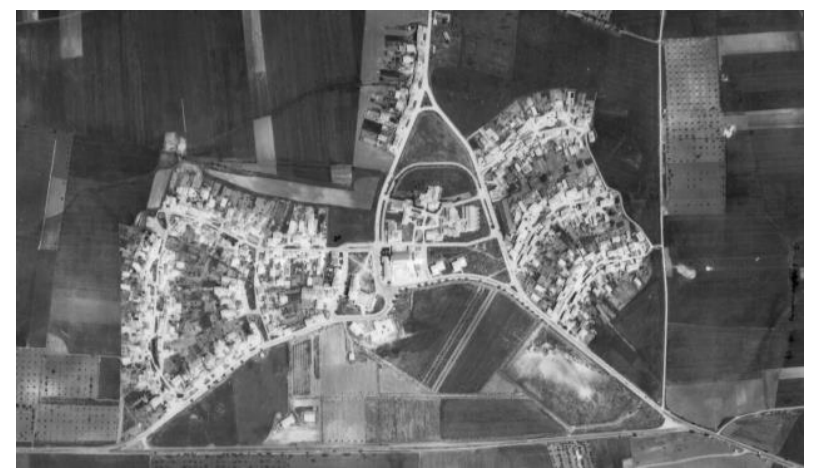

Figure 1. Aerial photo of the original rural village of U.N.R.R.A. Casas "La Martella" in Matera (C ICCD Archivio Aereofototeca Nazionale Image Copyright 1961).

However, the planning process of the village was strongly marked by the incompatibility in the management of the intervention by the two promoters, the U.N.R.R.A. Casas and the Reform Authority, especially in relation to the lack of public facilities originally planned, the vegetable plot quotas allocated to the farmers that were lower than expected, and the socio-economic changes that have thus determined the progressive abandonment and consequent widespread squatting in the existing buildings and in the pertinent spaces behind them which were intended for cultivation (Quaroni, 1981; Giura Longo, 1984). Moreover, in the last two decades, recent public and private building works (Ecopolis and Ater) in the north-west and north-east quadrants of the settlement have further interfered with the already compromised situation, being totally decontextualized with respect to the original urban and typological structure. Despite the current condition of marginality of the village with respect to the city and some situations of physical degradation of the building heritage and alteration of the urban layout, realistic strategies for a compatible recovery and reuse of the village are desirable, both in relation to the urban planning regulations in force and those in the process of being approved (the settlement to be safeguarded is considered zone A) and in relation to the agricultural vocation of the territory and the current needs of the settled population (Mininni, 2015).

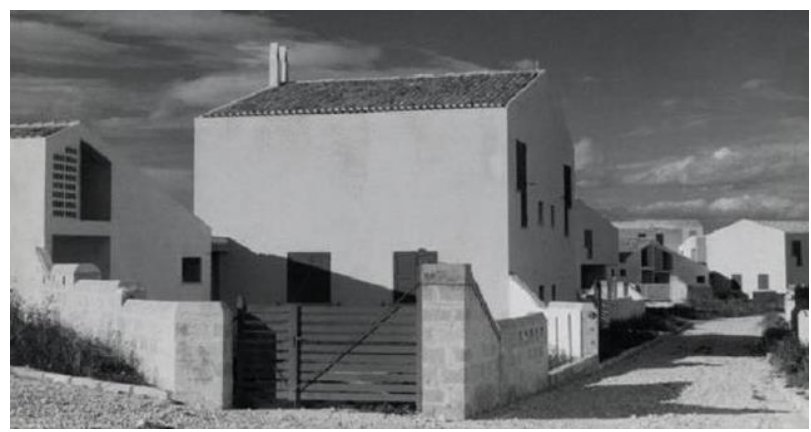

Figure 2. Historical photo of one of the housing aggregations of the new village "La Martella" (@) Archivio storico Triennale di Milano Image Copyright 1960). 


\section{RESEARCH AIMS AND METHODS}

\subsection{The survey of the current situation and the development of a holistic database for the systematisation of knowledge}

The research carried out on the case study of the rural village "La Martella" was articulated through an integrated workflow, combining both the use of traditional survey methodologies and the support of ICT tools and platforms that made it possible to classify, query and implement the data previously found. At the same time, we started from the research of historical and scientific literature, archival sources and project works of the case under examination and, at the same time, from the expeditious field surveys, through direct and indirect photographs and reliefs of the current situation of the existing building of the original nucleus. Subsequently, we proceeded with an initial screening and systematization of the collected data, in particular through the digitalization in $2 \mathrm{D}$ of a recent but not updated cartography for their consequent insertion and cataloguing in a special GIS type geo-referenced information platform (in QGIS environment) in which specific attributes linked to the information found were created for subsequent mapping according to the state of alteration of the original typologies and the degree of occupation of the related gardens. From these first classifications and elaborations we then proceeded with targeted queries in order to obtain quantitative and qualitative outputs on the state of alteration of the building fabric and of the pertinent spaces from which to extrapolate indications for hypothesis of intervention for requalification and recovery on an urban and building scale. At this point, the joint use of an HBIM type information model was decisive. This allowed for the detailed development of some geometric attributes at the various reference scales (from the settlement scale to the urban aggregates to the architectural one) through the connection of multiscale sub-models in a holistic 3D database (in Autodesk Revit environment), starting from the semantic attributes previously developed on the GIS type information system.

\subsection{The georeferenced GIS system for the evaluation of the current situation and the definition of intervention categories}

Starting from the preliminary survey work in the field to detect and document the current situation, as well as via the research and consultation of archive sources as a comparison tool, we proceeded to systematize the data found in a 2D cad base, with a prior update of the most recent cartography (scale 1:5000) also through shipping surveys and checks from orthophotos and cartographies available on the web. These cross-surveys have therefore made it possible to distinguish the uses of the buildings, the original ones and recent additions, the state of maintenance and degree of alteration of the building typologies of the historic centre, the precarious buildings (shacks and sheds, often illegal) and lastly the use of the characteristics of the pertinent areas (the original vegetable plots), in the latter case, surveying the paved and cultivated areas with their respective state of use (Figure 3). The acquisition and classification of this information provided the basic data for the subsequent development of a Georeferenced Information System (GIS) which made it possible to systematize this data in a specific platform (in the QGIS environment) for the development of subsequent targeted queries in order to elaborate intervention hypotheses for redevelopment and recovery. To facilitate the design phase of the database, the conceptual model based on block diagrams was used. The semantics thereof can be traced back to a relational data scheme (E-R schemes in reference to the entity-relationship model). The fundamental components of this ER model can be summarized in entities (sets of objects with common characteristics), in associations (logical link between entities) and in attributes (elementary properties of entities and associations). The structure of the geodatabase implemented for the area investigated, has followed simple rules based both on the geometric aspects of the territorial entities (points, lines, polygons) and on the data collected on the field (external tables containing the collected information).

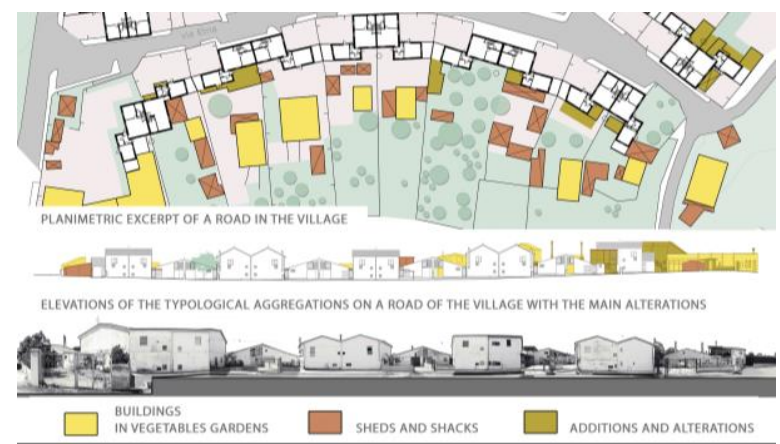

Figure 3. Onsite surveys of the main urban and building modifications (new buildings in vegetable plots, sheds and shacks, additions and alterations ) in the settlement.

The first step concerned the transposition of the updated map base from a CAD environment (dwg format, georeferenced in the WGS 84 - UTM 33N projection system) to a GIS environment: this step allowed to relate the geometric component (points, lines, but above all polygons) to the main data collected by the direct field survey (original building units, buildings in the gardens). The second step, concerned the detailed definition of the data model used: the issues addressed are related to different aspects and the geodatabase was organized per information layers. The third step concerned the elaborations, following the available data bases, for the definition of the specific thematic information layers (definition of the degree of building alterations, building intervention categories, urban planning indicators). In particular, with regards the evaluation of the degree of alteration, and with respect to the original characteristics of the individual building units, the elaborations of the databases were carried out through multiple queries on selected attributes (Figure 4).

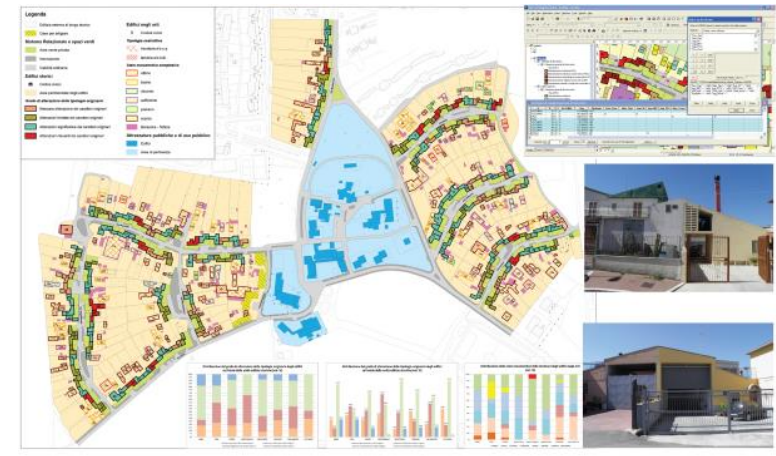

Figure 4. Definition of specific thematic information layers relating to alterations and the state of maintenance of the original public buildings in the chosen settlements.

In addition, the main urban planning indexes were also calculated, following the perimeter of the areas assigned to the existing buildings. Lastly, the fourth step entailed processing the statistics, that were reverted through diagrams, which summarize some characteristics of the settlement system analyzed on the basis of the processing of the most significant data acquired and reported in the database. These steps in the georeferenced database, made it therefore possible to identify and classify the main alterations of the 
housing units (elevations and additions; modifications and additions of external openings; chromatic and material dissonances; addition of external structures on the main front; closure and alteration of agricultural annexes) for a subsequent assessment of the current situation. In general, and with reference to the most compromised cases, there are not many widespread types of alterations that have irreversibly transformed the original features of the historical buildings. On the contrary, there are widespread alterations, especially of the external openings which, under certain conditions, could be reversible. The analyses carried out in the knowledge phase of the current situation of the historic "Borgo de La Martella" (Figure 5), starting from the data and information organized in the GIS, have represented the reference for the evaluation of the categories of intervention on each existing building. Lastly, two specific goals seem to be achievable under certain conditions: on the one hand, protecting the landscape image of the village through a planning that limits its expansion by providing an area in respect of the historical settlement; on the other, an active action of requalification of the existing settlement through a control of the building transformations and adequate incentives for the recovery of the historical buildings, of public facilities and the regeneration of their pertinent areas.

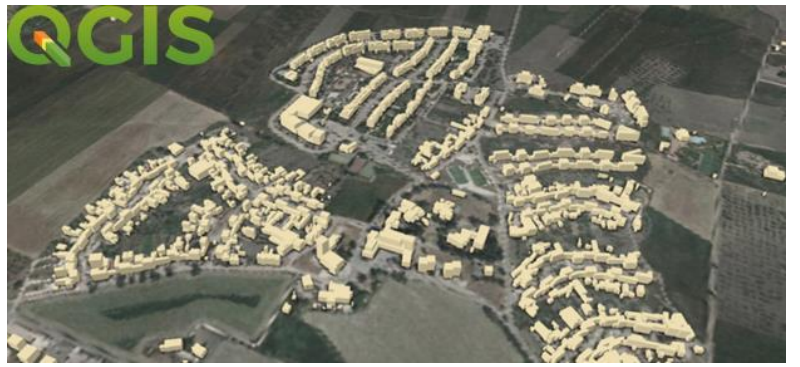

Figure 5. The georeferenced 3D model in QGIS environment.

\subsection{The HBIM multiscale information model of the village: from the scale of the settlement, to the scale of the urban aggregates, to that of the single building units}

Along with the elaborations and analyses carried out in GIS, the development of a specific information model through the use of an HBIM platform for the multiscale analysis of the village "La Martella", was created starting from the metadata catalogued and organized previously, for their subsequent implementation specifically in relation to geometric attributes. The development of a precise holistic and implementable CDE (Common Data Environment) database has allowed for the definition of a workflow on the Autodesk Revit software through the integrated connection of different digital models, each corresponding to a different scale of intervention referred to a different level of information development (Figure 6), through the use of a specific LOD (Level Of Development) as required by the current Italian legislation (UNI 11337, 2017) and through a process of "architectural disarticulation" and "digital reconstruction" (Gigliarelli et al., 2018).

The first level of the planned survey corresponds to a general information container (level 0, LOD A) through which the different models can be connected simultaneously or separately according to the estimated needs and analyses: the field of intervention to which this first macro model can be ascribed, refers to the planning on a territorial scale (General Regulatory Plan or its variants, etc.). The next step provides for the passage from the territorial scale to the one defined as "macro-urban", i.e. the settlement fabric or significant parts thereof (level 1, LOD B): this survey scale, which is referable to the strategic urban planning field (e.g. the Detailed Plan), allows for an analysis through the connection of metadata and non-geometrical attributes found on the digital model, with the definition solely of external volumes (through the "concept mass" tool) and the use of special thematic sheets through sets of shared parameters and view filters. In this case it has been possible to implement some information related, for example, to the degree of alteration of the historical building typologies or to the state of occupation and transformation of the related areas already developed on the GIS platform (Figure 7).

The following reference scale (Figure 8) is related to urban aggregates and blocks, defined as "micro-urban" (level 2, LOD C) with the introduction of libraries of basic parametric objects that can be categorized (families) and to which specific attributes (type and instance) can be associated for a preliminary quantitative analysis (e.g. the size of openings, the total volume or surface of walls, roofs and floor slabs, etc.): the reference scope is that of urban design or restoration (e.g. the Urban Recovery Plan).

The last scale investigated in this first phase of the $\mathrm{PhD}$ research corresponds to the one related to the single building unit, defined as "architectural" (level 3, LOD D), in which the single parametric components previously introduced in the urban aggregates survey scale are developed and implemented. These stem from the insertion of specific geometric and semantic attributes referred to each element of the model for the preparation of special digital data sheets, which can be constantly implemented and updated (Figure 9). The scope of intervention of this last level of information corresponds to the executive design or building restoration (e.g. the renovation of a roof or floor, etc.). The analyses carried out constitute the basis for the subsequent intervention strategies envisaged for the recovery and re-functionalisation of the rural settlement, with a view to compatibility with the original intended uses: from the building and urban recovery of the original types, to the redevelopment of the relevant vegetable plots, up to the regeneration of the existing public areas, providing for the repaving and pedestrianisation of the central area of the village.

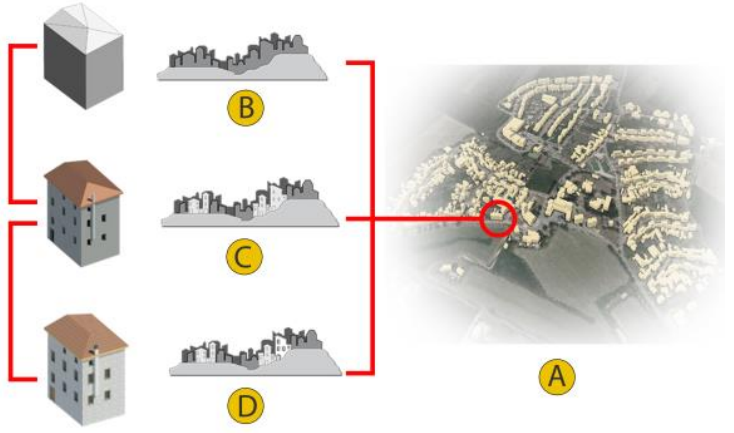

Figure 6. Definition of the multiscale workflow developed inside the HBIM information model of "La Martella".

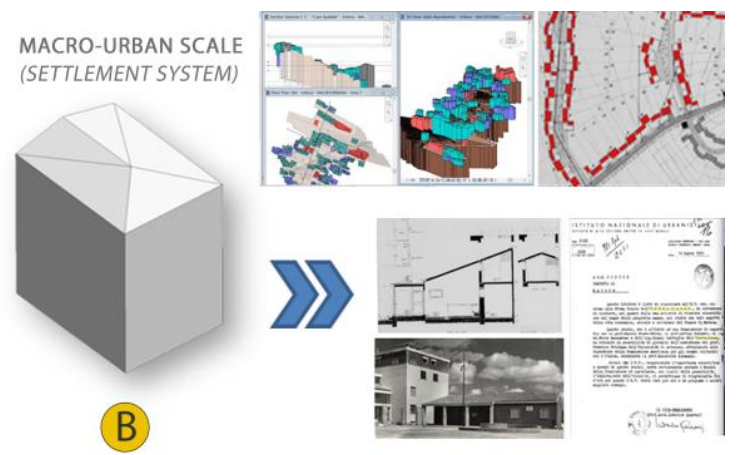

Figure 7. The Macro-urban scale (B): connection of metadata to the conceptual masses. 


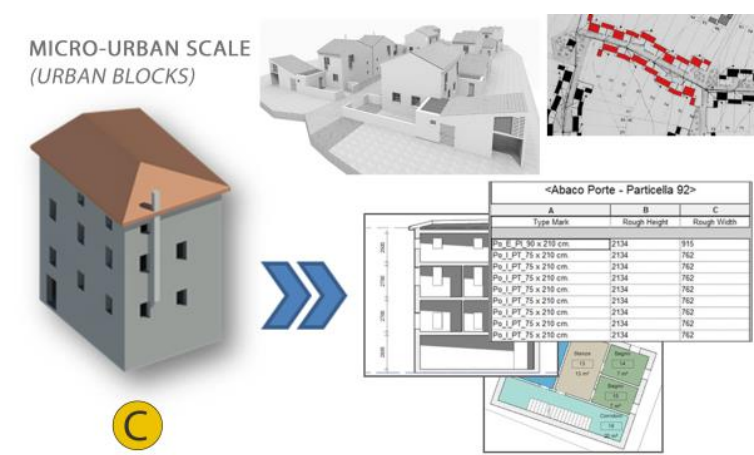

Figure 8. The Micro-urban scale (C): introduction of libraries of basic categorized parametric objects.

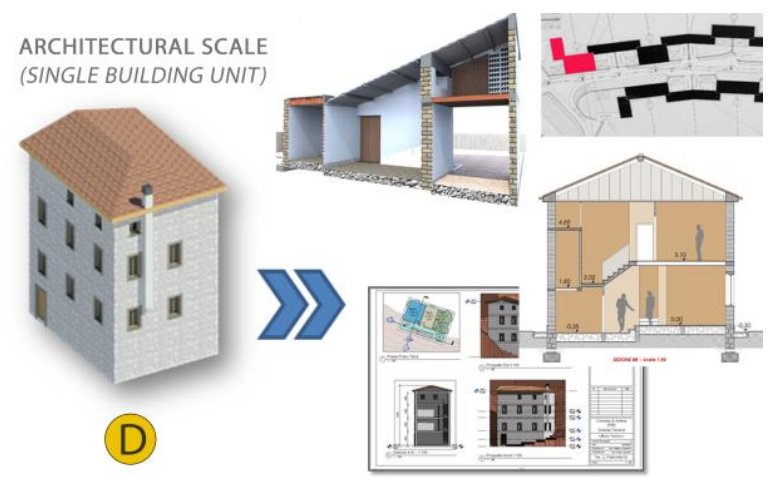

Figure 9. The Architectural scale (D): from the urban blocks to the single building unit. Development and implementation of the single parametric components.

\section{FIRST RESULTS OF THE OPERATIVE RESEARCH}

4.1 Results achieved and problems reported in the management of the digital database and research methodologies

The benefit of this integrated and multiscale survey methodology is particularly useful for the systematization and use of different types of data between the different intervention scales: this process has allowed for the identification of the irregularities present between the different information models, for the aim of a more accurate analysis of the existing situation, at the basis of the subsequent recovery hypotheses. Compared to GIS systems that do not allow for a simultaneous visualization of several views (2D and $3 \mathrm{D}$ ) with the possibility of instant changes throughout the model, the use of the BIM platform has allowed to cross-check the interferences between the different models and within each of them among the different geometric objects inserted. On the contrary, in the BIM environment, it was more complicated to implement and manage non-geometric attributes through which to perform multiple queries and thematic mapping, which were more manageable in the GIS georeferenced database. From this point of view, the targeted queries on the thematic mappings elaborated in the QGIS environment allowed for a subsequent adequate evaluation of the outputs obtained for the choice of specific intervention categories on the original building of the rural settlement as well as the state of use of the relevant areas. The main difficulties found are first of all related to the lack of an adequate two-dimensional cartographic starting base, and of often conflicting assorted archive sources: these problems constituted an initial difficulty in systematizing the data found in a 2D CAD environment, for subsequent transfer to the respective digital platforms used. A second problem detected, partly connected to the first, is related to the management of the georeferenced GIS database with the different information models in BIM environment, especially in relation to the loss of information connected to specific attributes shared between the two systems. With reference to recent studies and researches in the field, the attempts of interoperability between the two software environments have so far led to different experimental approaches depending on the individual case studies and applications, according to specific goals (Saygi et al., 2013; Barazzetti, Banfi, 2017; Ohori et al., 2017; Matrone et al., 2019). In the field of built heritage sites some research has shown good results in perspective thanks to the combined use of BIM (Revit and Archicad) and GIS (Arcgis) tools through shared platforms such as FME, BIM server, GeoBIM, among others (Dore, Murphy 2012; Vacca et al, 2018); some has focused more on bidirectional data transfer between the open BIM and GIS interoperability standards, the IFC data model (Industry Foundation Class) and the CityGML GIS model (City Geography Markup Language), but found some gaps both from a semantic and a geometric point of view (Tobiáś 2016; Matrone et al, 2019) and some, in the interoperability between the two systems through the Autodesk Infraworks platform for multiscale analysis (Baik et al., 2015; Barazzetti, Banfi 2017). This last approach to GIS-BIM interoperability was chosen for this case study, already in the testing phase. At this point the first results were achieved, thanks to the recent partnership between Esri (Arcgis) and Autodesk (Revit) which seem to provide evaluation elements that are favorable for a potentially greater integration between the two systems, especially for the sharing of geometric and semantic information. In general, the combined use of both digital systems has been of fundamental importance for a more systematic analysis of the existing settlement of "La Martella", through the structuring of a special database in which to transfer and share heterogeneous information between the two, particularly in relation to the different types of surveys and reliefs carried out in accordance with the different intervention scales provided.

\section{CONCLUSIONS AND RESEARCH PERSPECTIVES}

The ongoing research presented in the contribution, has allowed for the development of a methodology for the construction of cognitive processes related to the modern building heritage of historicaltestimonial value, through the use of GIS and BIM digital systems and tools so as to support the analysis and investigation of the existing situation of the U.N.R.R.A. Casas rural village "La Martella" in Matera. This integrated approach between the two technologies, applied to an emblematic case of Italian architecture of the second half of the Twentieth century, has constituted a first step in the experimentation of a holistic and feasible database in which to share and query different types of information, constantly implementable and editable over time. The combined use of the two digital tools was crucial, especially in the first phase of the analysis of the existing situation, which was to outline specific guidelines for a possible and credible recovery of the residential buildings of the original village, through targeted conservation and enhancement strategies (AA.VV., 2009; Bilò, Vadini, 2013; Mininni, 2015). The analyses and surveys, both direct and indirect, on the current situation of the original buildings, have provided different and interesting suggestions for consideration regarding the current conditions and methods of use thereof and for a possible partial or complete recovery and reuse, especially in relation to the current needs of the resident population, undoubtedly different from those of the first inhabitants who settled there in the fifties. Preliminary surveys and analyses - carried out through the joint use of traditional methods (photographic surveys, metric surveys) and 
more innovative technologies (laser scanner, photogrammetry, georeferenced GIS platform), have provided information and data on all the original and recent constructions of the current village; for example, it has been possible to census and map in a timely manner the conditions of the alterations and tampering of the houses originally intended for the farmers, most of which have undergone building renovations over the decades, at times with an increase of the original volumes. Many works carried out, especially in recent years, are often unauthorized and in any case without any regulatory criteria at the basis of the changes made. Major alterations to the original settlement characteristics have been found especially in the unauthorized constructions carried out at the rear end of the houses, in the spaces originally destined for vegetable plots. The alterations, both quantitative and qualitative, between the permeable and paved surfaces are notable compared to the initial situation (also by comparison with the orthophotos of the Sixties), and so are the various alterations of the original characteristics of the residential buildings: inappropriate openings/closures, elevations and additions, chromatic and material dissonances, closure/opening of the agricultural annexes. The different situations have been highlighted in the geo-database realized. If, on the one hand, the overall image of the original settlement is currently partly compromised - due to the alterations to the historical buildings and to the successive expansions of the village with the implementation of residential, public and private building works which are completely decontextualized with respect to the original layout of the village - on the other, today it is still possible and desirable to find a possibility of redevelopment of the historical building fabric. In this perspective, the rediscovery of the historical-testimonial value of this rural settlement is crucial, both nationally and internationally, especially by the research bodies (Do.co.mo.mo. association, Adriano Olivetti Foundation, etc.), as well as a greater awareness for the need to protect the characteristics of the original settlement by the local public administrations and especially the residents themselves, thanks also to the establishment of cultural associations and decentralized committees (for example, the recent constitution of the "Comitato Quaroni del Borgo "La Martella").From this perspective, from the analyses carried out on the existing situation, two possible strategies have emerged, aimed at the requalification and regeneration and the urban and building recovery of the original plant. On the one hand, a requalification of the public spaces along the public roads (the original neighborhood units re-proposed among the farmers' houses) and near the public facilities, thereby completing the functional organization of the areas in accordance with the original design, also re-proposing original or compatible materials. On the other hand, a targeted action of restoration of the architectural features present on the main fronts of residential and public buildings, also with the use of contemporary technologies and materials that allow for a typological and chromatic recovery compared to the original ones. Finally, with regard to the unauthorised buildings and alterations present in the vegetable plots behind the residential buildings, demolition actions could be envisaged for those that are decaying or precarious (shacks and sheds) or, alternatively encourage the demolition and not the reconstruction of those volumes no longer used nor strictly necessary for the minimum functionality of historical houses. Through, for example, the provision of perequative urban planning models, in these cases, the transfer of the building rights assigned to buildings in areas surrounding but external to the historical settlement could be considered. The intervention strategies proposed on the urban and building fabric of the village "La Martella", could find a useful technical support in the interaction and integration of the two working environments of GIS and BIM for the design and management interventions, especially in relation to the different goals and working methods and, above all, in relation to the different scales of intervention (Saygi et al., 2013; Baik et al, 2015; Barazzetti, Banfi, 2017; Ohori et al., 2017): georeferenced territorial systems were more suitable for analysis at the territorial and urban settlement scale, while BIM technologies allowed for the development of specific multiscale models, from the settlement scale to the architectural scale, passing through the intermediate scale of urban aggregates (Dore, Murphy, 2012; Baik et al., 2015; Gigliarelli et al., 2018; Vacca et al., 2018). With particular reference to the state of maintenance of the original building, it is essential to operate in the environment and according to BIM approaches, both in terms of architectural design as well as structural and plant engineering aspects, especially in relation to the need to define design solutions that are appropriate for the current situation and housing demand that express different needs other than the original one. The use of traditional construction techniques (load-bearing masonry in tuff, wood and local stone), together with innovative structural devices for the time (the SAP type brick slab) must be carefully considered in the structural checks that must inevitably take into account both the seismic adaptation aspects of the buildings and the possible inclusion of new building materials and technologies, with a view to reconciling a proper recovery of the original features of the buildings with interventions that allow for a better performance thereof in relation to the current living requirements. In those cases, where it is not possible to recover the original buildings, also due to their excessive degradation or state of alteration and tampering, demolition and philological reconstruction of residential buildings could also, exceptionally, be considered. Software such as Autodesk Revit includes the integrated use of different working environments (architectural, structural and plant engineering); in this way, it will be possible to carry out an in-depth analysis of the current situation of each building, the state of its materials, chromatic, architectural and structural degradation and, through the "interference analysis" (clash detection) it will also be possible to monitor any incompatibilities between the different models and evaluate the most advantageous solutions to be adopted for each building (Eastman 2011; Dore, Murphy, 2012; Brumana et al., 2013). In a future development of the research, the combined use of other methodologies and digital tools for a holistic knowledge of the current settlement of the village "La Martella" will be possible so as to define specific intervention strategies aimed at a more comprehensive and organic approach towards urban regeneration: from the urban and architectural point of view, to plant engineering and technology, especially with regards the costs and benefits that each choice may entail. This approach to the integrated management of information processes related to the case study, was crucial for the development of strategies underlying the intervention choices for the recovery of the historical settlement of the rural village. In this perspective, the implementation of interoperable platforms between the two systems (Autodesk Infraworks) is intended, in order to hypothesize precise choices on some degraded residential buildings and public facilities. Also of fundamental importance is the preparation of a special digital manual for the recovery of "La Martella", starting from the surveys and data structured in this shared database, with the possibility of implementing the information present, with a view to future management and maintenance of the heritage built through IT tools (as required by Ministerial Decree no. 560/2017) within the local government, for the sharing of information models among the various stakeholders involved. 


\section{REFERENCES}

AA.VV., 2009. Strategie di valorizzazione e gestione per il patrimonio architettonico: sguardi e proposte. Collana Intangibili, Quaderni della Fondazione Adriano Olivetti, Roma-Ivrea.

Acierno, M., Cursi, S., Simeone, D., Fiorani, D. 2017. Architectural heritage knowledge modelling: An ontologybased framework for conservation process. Journal of Cultural Heritage, 24, 124-133.

Aymonino, C., 1959. Matera: mito e realtà. Casabella Continuità, 231, 7-12.

Baik, A., Yaagoubi, R., Boehm, J., 2015. Integration of Jeddah Historical BIM and 3D GIS for documentation and restoration of historical monument. Int. Arch. Photogramm. Remote Sens. Spatial Inf. Sci., XL-5/W7, 29-34.

Barazzetti, L., Banfi, F., 2017. BIM and GIS: when parametric modeling meets geospatial data. ISPRS Ann. Photogramm. Remote Sens. Spatial Inf. Sci., IV-5/W1, 1-8.

Berdelli, P. G., Capomolla, R., Vittorini, R., (Eds.) 2003. L' architettura INA Casa (1949-1963): aspetti e problemi di conservazione e recupero. Gangemi, Roma.

Bilò, F., Vadini, E., 2013. Matera e Adriano Olivetti. Collana Intangibili, Fondazione Adriano Olivetti, Roma.

Brumana, R., Georgopoulos, A., Oreni, D., Raimondi, A., Bregianni, A. 2013. HBIM for documentation, dissemination and management of built heritage. The case study of St. Maria in Scaria d'Intelvi. Int. Journal of Heritage in Digital Era, 2(3), 433-451.

Chiabrando, F., Sammartano, G., Spanó, A. T., 2016. Historical Building Models and their handling via 3D survey: from points clouds to user-oriented HBIM. Int. Arch. Photogramm. Remote Sens. Spatial Inf. Sci., XLI-B5, 633-640.

De Carlo, G., 1954. A proposito di La Martella. Casabella Continuità, 200, 5-8.

Di Biagi, P., 2001. La grande ricostruzione. Il piano Ina Casa e l'Italia degli anni '50. Donzelli Editore, Roma.

Dore, C., Murphy, M., 2012. Integration of Historic Building Information Modeling and 3D GIS for Recording and Managing Cultural Heritage Sites. 18th Int. Conf. on Virtual Systems and Multimedia.

Doria, P., 2010. Ritorno alla città laboratorio. I quartieri materani del risanamento cinquanta anni dopo. Edizioni Antezza, Matera.

Eastman, C., Teicholz, P., Sacks, R., Liston, K., 2011. BIM Handbook. 2. John Wiley \& Sons Inc., Hoboken.

Gigliarelli, E., et al. 2017. Heritage Bim, Numerical Simulation and Decision Support Systems: an Integrated Approach for Historical Buildings Retrofit. Climamed 2017. Matera, May 12-13, 2017.

Gigliarelli, E., Pontrandolfi, R., Calcerano, F., 2018. HeritageBIM: The integrated management of the historical centres, the case study of Artena. International SITdA Conference: The production of the project. Reggio Calabria, June 14-15, 2018.

Giura Longo, T., 1984. Dopo La Martella. Note di impostazione e linee di indirizzo progettuale. Parametro, 124(3), 30-37.

Giura Longo, T., 2003. Matera: i Borghi e i Quartieri degli anni '50. Siti, 02, Matera.
Gorio, F., 1954. Il villaggio La Martella. Autocriticà. Casabella Continuità, 200, 31-38.

Kolbe, T. H., Gröger, G., Plümer, L., 2005. CityGML: Interoperable Access to 3D City Models. Geo-Information for Disaster Management ..., Heidelberg, Berlin, 883-899.

Ma, Z., Ren, Y., 2017. Integrated Application of BIM and GIS: An Overview. Procedia Engineering, 196, 1072-1079.

Matrone, F., Colucci, E., De Ruvo, V., Lingua, A., and Spanò, A., 2019. HBIM in a semantic 3D GIS database. Int. Arch. Photogramm. Remote Sens. Spatial Inf. Sci., XLII-2/W11, 857-865.

Mininni, M., 2015. Nuove società e inerzia dello spazio aperto: Matera e gli esiti di un progetto riformista agro-urbano. Territorio, 72, Franco Angeli, Milano, 59-66.

Ohori, K. A., Biljecki F., Diakité, A., Krijnen, T., Ledoux, H., Stoter, J., 2017. Towards an integration of GIS and BIM data: what are the geometric and topological issues?. ISPRS Ann. Photogramm. Remote Sens. Spatial Inf. Sci., IV-4/W5, 1-8.

Piccinato, L., 1955. Matera, i Sassi, i nuovi borghi ed il Piano regolatore. Urbanistica, 16(5).

Pontrandolfi, A., 2002. La vergogna cancellata. Matera negli anni dello sfollamento dei Sassi. Edizioni Altrimedia Eumenidi, Matera.

Quaroni, L., 1981. Matera e La Martella: piani e progetti. La città fisica. Laterza, Bari.

Raguso, A., 2010. Matera dai Sassi ai Borghi 1952/1964. Un modello di gestione del territorio. Altrimedia Edizioni, Matera.

Saygi, G., Agugiaro, G., Hamamcığlu-Turan, M., Remondino, F., 2013. Evaluation of GIS and BIM Roles for the Information Management of Historical Buildings. ISPRS Ann. Photogramm. Remote Sens. Spatial Inf. Sci., II-5/W1, 283-288.

Spallone, R., Piano, A., Piano, S., 2016. B.I.M. e beni architettonici: analisi e rappresentazione multiscalare e multidimensionale di un insediamento storico. DISEGNARECON, 16, 13.1-13.13.

Tafuri, M., 2002. Storia dell'architettura italiana. 1944-1985. Einaudi Editori, Torino.

Talamona, M., 2001. Dieci anni di politica dell'Unrra Casas: dalle case ai senzatetto ai borghi rurali nel Mezzogiorno d'Italia (1945 1955). Il ruolo di Adriano Olivetti. Costruire la città dell'uomo. Adriano Olivetti e l'urbanistica. Ed. di Comunità, Torino, 173-204.

Tobiáš, P., 2016. BIM, GIS and Semantic Models of Cultural Heritage Buildings. Geoinformatics FCE CTU, XV- 2, 27-42.

Torabi Moghadam, S., Lombardi, P., Ugliotti, F. M., Osello, A., Mutani, G. 2016. BIM-GIS Modelling for Sustainable Urban Development. SBE16 Towards Post-Carbon Cities, 2, 339-50.

UNI 11337:2017 - Gestione digitale dei processi informativi delle costruzioni - BIM.

Vacca, G., Quaquero, E., Pili, D., Brandolini, M., 2018. GIS-HBIM integration for the management of historical buildings. Int. Arch. Photogramm. Remote Sens. Spatial Inf. Sci., XLII-2, 1129-1135.

Volk, R., Stengel, J., Schultmann, F., 2014. Building Information Models (BIM) for existing buildings - literature review and future needs, Automation in Construction, 38, 109-127. 